\title{
AUTOMATIC DETECTION OF DOMINANT CROP TYPES IN POLAND BASED ON SATELLITE IMAGES
}

\author{
Joanna PLUTO-KOSSAKOWSKA ${ }^{1}$, Magdalena PILARSKA ${ }^{1}$, \\ Paulina BARTKOWIAK ${ }^{2}$ \\ ${ }^{1}$ Warsaw University of Technology, Faculty of Geodesy and Cartography, \\ Warsaw, Poland \\ ${ }^{2}$ Institute for Earth Observation, Eurac Research, Bolzano, Italy \\ e-mails: joanna.kossakowska@pw.edu.pl (JPK), \\ magdalena.pilarska@pw.edu.pl (MP),paulina.bartkowiak@eurac.edu (PB)
}

\begin{abstract}
The assumption of the European Union Common Agricultural Policy is to maintain good agricultural practices for sustainability in the environment. A number of requirements are imposed on farmers, including the maintenance of permanent grassland, fallow land or crop diversification. To meet these requirements, the European Union guarantees subsidies, but at the same time fields must be monitored focusing on crop identification. The limitation of field inspection and substituting it with crop recognition using satellite images could increase the effectiveness of this procedure. The application of satellite imagery in automatic detection and identification of dominant crops over a large area seems to be technically and economically sound. The paper discusses the concept and the results of automatic classification based on a Random Forests classifier performed on multitemporal images of Sentinel-2 and Landsat-8. A test site was established in a complex agricultural structure with long and narrow parcels in the south-eastern part of Poland. Time-series images acquired during the growing season 2016 were used for multispectral classification in different configurations: for Sentinel-2 and Landsat-8 separately and for both sensors integrated. Different Random Forests approaches and post-processing methods were examined based on independent data from farmers' declarations records, reaching the best accuracy of over $90 \%$ for crops like winter or spring cereals. Overall accuracy of the classification ranged from $72 \%$ to $91 \%$ depending on the classification variant. The elaborated scheme is novel in the context of Polish complex agricultural structure and smallholders.
\end{abstract}

Keywords: Crop identification, multitemporal classification, Random Forests, Sentinel-2, Landsat-8, greening practices

\section{INTRODUCTION}

The ability to recognize and to map crops is essential to obtaining information about what and when is grown in predefined areas. Such information can be used for forecasting yield, for example, the MARS Crop Yield Forecasting System (MARS Bulletins, 2020), statistical analysis of crop production (Ray et al., 2013; Łączyński, 2014), crop rotation management, assessment of damage to crops caused by atmospheric phenomena (Wicka, Parlińska, 2019) or monitoring of agricultural activities (Ji et al., 2018; Sonobe et al., 2017). The key steps related 
to crop mapping include two elements: the identification of crop types and the delineation of their extent (borders). Traditional methods of obtaining this information are based on census and ground surveying. However, in order to standardize and automate the crop measurements, remote sensing techniques can be utilised. They can provide common data collection and more robust strategies for information extraction. Information from remotely sensed data can be input into a geographic information system (GIS) such as a Land Parcel Identification System (LPIS) and combined with ancillary data on ownership, management practices and so on. Other EO data advantages in crop classification include large spatial coverage and timeliness. Therefore, the use of satellite images to derive information about the crop types is reasonable and can be used to monitor greening practices.

\section{Greening practices}

As part of the current agricultural policy in the EU (2014-2020), Member States are obliged to implement the greening payment. The basic greening requirements were established in EU regulation 1307/2013 of the European Parliament and the Council and implemented by Commission Implementing Regulation (EU) No 641/2014. These Regulations differentiate the greening obligations depending on the specific situation in certain regions of EU countries, category of farmers and type of agricultural land. Since 2015, as a rule, all the farmers applying for the single area payment have received a payment for agricultural practices beneficial for the climate and the environment, that is, the greening payment. These practices are mandatory for all the farmers who have applied for subsidies in all EU countries and include three requirements: crop diversification (CD), maintenance of permanent grassland (PG), and maintenance of an ecological focus area (EFA) (Regulation (EU) No 1307/2013; Devos et al. 2017). Farmers subject to the implementation of these practices are obliged to provide the individual crop species and the areas of these crops, and other ecological focus area elements through GIS information systems (in the application for payment). Presented below are the general conditions of individual practices.

Crop diversification (CD) applies to agricultural holdings with an area of more than 10 ha of arable land. It consists of maintaining an appropriate number of crop species and cultivation area on the arable land of a farm in a given year. For the purposes of diversification, a crop means a culture of any species, land lying fallow and grasses or other herbaceous forage. The number of crops is determined and the share of various crops is calculated in a certain period of the year in which the application for payment has been submitted. This condition results in the necessity to use satellite techniques in order to support the verification of greening practices in a large region. It is extremely important in the case of Poland because of the huge number of holdings (according to Paying Agency over 1.4 million), which require an evaluation of compliance with the crop diversification practice.

The maintenance of permanent grassland (PG) applies to all the holdings declaring crop groups for direct payments. Mandatory PG practice consists of two elements, namely, the obligation to maintain the designated environmentally valuable permanent grasslands situated in Natura 2000 areas at the holding level and the obligation to maintain the PG acreage unreduced in relation to the acreage of PG established in the reference year 2015 (Milenov et al., 2015). Therefore, it is important to elaborate on the method of PG detection as a crop type and it is considered in this study as well.

The maintenance of ecological focus areas (EFA) applies to all the agricultural holdings with arable land of more than or equal to $15 \mathrm{ha}$. As a rule, farmers are obliged to ensure that at least $5 \%$ of the arable land of the holding is an ecological focus area. The EFA elements to be verified constitute a long list. Some of them are point or linear elements, which do not meet the recognition criterion for images with a resolution of $10 \mathrm{~m}$ and $20 \mathrm{~m}$ (likewise Sentinel-2). The 
EFA spatial elements can also constitute parcel objects, for example, nitrogen-fixing crops, which raises the possibility of their recognition in satellite images. The crop groups constituting a declaration of EFA as an area of unstable (variable and temporary) elements are marked as EFA1 - land lying fallow, EFA15 - areas with nitrogen-fixing crops, EFA12 - areas with short rotation coppice and EFA13 - afforested areas (Loudjani et al., 2015).

On 1 June 2018, the European Commission presented legislative proposals (Proposal for a REGULATION (...) COM/2018/392 final) on the common agricultural policy (CAP) for the period 2021-27. The proposals aim to ensure that the CAP can continue to provide strong support for European farming, enabling prosperous rural areas and the production of highquality food. The proposals will also allow the CAP to make a significant contribution to the European Green Deal, especially with regard to the "farm to fork" strategy and biodiversity strategy. In order to achieve these broad goals, the Commission has set out nine specific objectives of the CAP: to ensure a fair income for farmers; to increase competitiveness; to rebalance the power in the food chain; climate change action; environmental care; to preserve landscapes and biodiversity; to support generational renewal; vibrant rural areas; to protect food and health quality. To ensure stability and predictability, income support will remain an essential part of the CAP. Partially, basic payments will continue to be based on the farm's size in hectares. However, the future CAP wants to prioritise small and medium-sized farms and encourage young farmers to join the profession. This is why the Commission proposes a higher level of support per hectare for small and medium-sized farms. Mandatory requirements include crop rotation instead of crop diversification as well as protection of the environment and preservation of landscapes and biodiversity (Proposal for a REGULATION (...) COM/2018/392 final).

Knowledge and innovation are essential for a smart, resilient and sustainable agricultural sector. The CAP of the future will both encourage increased investment in research and innovation and enable farmers and rural communities to benefit from it. Therefore, it is essential to build stronger agricultural knowledge and innovation systems (AKIS) to boost initiation and development of innovative projects, to disseminate their results and to use them as widely as possible. Successful AKIS strategies include four main groups of action: enhancing knowledge flows and strengthening links between research and practice; strengthening all the farm advisory services and fostering their interconnection within the AKIS; enhancing crossthematic and cross-border interactive innovation; supporting the digital transition in agriculture (EU SCAR AKIS, 2019).

Considering the issues discussed above, it is necessary to find the optimal methods of satellite image processing to derive information about the different crop types. Due to cloud cover and the satellites revisits over Europe, the optical image acquisition is limited in a certain period of the year. Therefore, various scenarios of image acquisition from different optical sensors and their limitations should be considered. Since Sentinel-2 and Landsat-8 images could complement each other, they are a natural source of data for crop identification. Moreover, they can be processed in a common multispectral and multitemporal classification. However, this methodology raises some questions to which this study would like to answer.

\section{OVERVIEW OF REMOTE SENSING METHODS APPLIED FOR CROP IDENTIFICATION}

The most commonly used methods of automatic crop recognition include multitemporal classification performed with Machine Learning methods such as Random Forest (Inglada et al., 2015; Inglada et al., 2016; Sitokonstantinou et al., 2018: Grabska, 2017), Neural Networks (Kussul et al., 2015a; Shelestov et al., 2017; Stankiewicz, 2006; Asgarian et al., 2016), Support Vector Machine (Inglada et al., 2015; Sitokonstantinou et al., 2018; Shelestov et al., 2017; 
Asgarian et al., 2016; Schmedtmann and Campagnolo, 2015; Yang et al., 2011). However, other methods are also used, such as Maximum Likelihood (Yang et al., 2011; Matton et al., 2015; Ianninia et al. 2013) or K-means (Matton et al., 2015). It is difficult to discuss the advantages of any method over the others, since the final classification result depends not only on the adopted processing method, but also on many other factors such as, above all, training data (quality and quantity), input data type (optical, radar images or their derivatives), data collection period, crop species as well as the agricultural structure in the research area. Although the first three methods, Random Forest (RF), Neural Network (NN) and Support Vector Machine (SVM), produce accurate results, RF requires a lower number of parameters, which minimizes the adjustment of algorithm variables. Also, comparing to other methods, RF is faster and more effective in future implementation (Belgiu et al., 2016). Therefore, it is a robust method from the automation perspective due to its most efficient choice of classification parameters. Pixelbased and parcel-based classification approach has been used equally frequently. The use of a chosen approach depends on the availability of segmentation algorithms (Li et al., 2016) and the ability to generate reference borders for crops/parcels (Kussul et al., 2015a). However, the pixel-based approach prevails, whereas the other approach is an aggregation of the classification result to the parcel. Additional filtration for smoothing the image and liquidating accidental single pixels (Valero et al., 2016) is also often used in the post-processing phase.

The most popular crops described in literature (Sitokonstantinou et al., 2018; Matton et al., 2015) are the ones cultivated in the temperate climate in the northern hemisphere: cereals, rapeseed, maize, sugar beet and grassland. The number of recognized species is usually 5-6 crop classes or groups and does not exceed 12-15. The more species to be identified, the more difficult the task is and, therefore, the lower the general classification result accuracy. It stems from the physical, phenological and, therefore, spectral resemblance of similar species within the same group (e.g., leguminous), for which it is difficult to find separate spectral signature. Consequently, they are 'confused' in the classification process, and the final classification result is poor. Classes representing non-agricultural areas such as water, urban areas and forests are also included in many studies (Skakun et al., 2016), which causes an increase in the general accuracy assessment and supports visualization or further analyses regarding the land cover itself. Earlier examples for SPOT4, Landsat8 and RapidEye (Inglada et al., 2016) for various research areas in the world where 5-6 crop types are identified produced very different results, from the best in the United States of Overall Accuracy (OA) equal to 91\% to the worst for test areas in Madagascar or Burkina Faso, where OA varied from 30\% to 50\%. The commonly used approach to 'crop/non-crop' classification, that is, for two classes, resulted in accuracy at the average Overall Accuracy (OA) level of $85 \%$ and it refers to the possibility of distinguishing agricultural (arable) lands from non-agricultural lands (such as forests, water and built-up areas) without indicating specific crop types (Matton et al., 2015; Valero et al. 2016). It should also be highlighted that the number of satellite scenes and the date of their acquisition is important when performing a multitemporal analysis. On the one hand, there is a wish to obtain the maximum possible number of scenes from the whole growing season (e.g., registration of every possible flight) but, on the other hand, there are cloud cover limitations for optical images as well as equipment constraints regarding processing and archiving a huge volume of data. The experiments described in literature (Matton et al., 2015; Foerester et al., 2012) indicate the need to include at least 4 periods of the growing cycle: 1 . the growing of crops on bare soil after tillage and sowing; 2 . a higher growing rate than natural vegetation types; 3 . a well-marked peak of green vegetation, and 4 . a fast reduction of green vegetation due to harvest and/or senescence.

Classification for large plots of land (>50 ha) using Landsat-8 data resulted in different accuracy levels depending on the classification method and agrarian system with the OA level of 60- 
90\% (Kussul et al, 2015a; Shelestov et al., 2017; Ianninia et al., 2013; Kussul et al., 2015b). Only a few experiments conducted on the Poland territory yielded overall accuracy of 77-84\%, whilst using SAR images mainly (Grabska, 2017; Stankiewicz, 2006). A similar agrarian structure to that of Poland and similar classification results were observed in Austria and Portugal, reaching an overall accuracy of 76-83\% (Immitzer et al., 2016), 95-96\% in Austria (Vuolo et al., 2018) and 68-84\% in Portugal (Li et al., 2016). Recently, some initiatives have been undertaken to solve the problem of crop identification around the world. The results can be observed in Sen2Agri and Sen4CAP, open access software for crops classification developed by ESA (esa-sen2agri.org, esa-sen4cap.org) (Bontemps et al., 2020) or OneSoil Map (map.onesoil.ai). The map released by OneSoil is based on Sentinel-2 imageries provided by ESA. Using machine learning algorithms, the Belarusian start-up recognizes 19 crops with F1 score from 0.92 to 0.96 accuracy (https://onesoil.ai/en/technologies) and calculates vegetation indices and nitrogen variable rates. The metrics included in the map are: parcel area, the crop and country crop rating. The algorithms allocate field boundaries with a 5-metre accuracy (Jaafar et al., 2015). These systems have limitations and can be used to give an overview of the distribution of crops for smallholders where the width of parcel is sometimes $10 \mathrm{~m}$ or less (see Figure 1).

Conclusions drawn from the literature at this stage can be summarized in a few general points. The main point is the great importance of the input set of training (and control) data, that is geometry and area, the number of representatives and range of species in crop groups. The results found in literature differ from each other, although they are difficult to compare due to the differences in cultivation and agrarian characteristics of the study areas. Research on the effectiveness of automatic crop identification is still strongly related to the characteristics of the region and crops, which is why it's results are rather unique.

\section{The goal and scope of research}

Hence, the scope of this study was to develop an automatic and effective (fast and qualitative) method of crops recognition in Poland considering the complex structure of plots using optical data under the greening requirements.

The study assumed the use of variability of vegetation spectral characteristics over time registered on optical data to distinguish crop types. The aim of the study was to indicate the usefulness of Sentinel-2 (S2) and Landsat-8 (L8) satellite data as a source of data for automatic identification of the selected crops in Poland. Within the established experiments, the accuracy of the results of the multitemporal classification was analysed based on the Random Forests algorithm in various input data configurations, that is, multispectral images from the Sentinel2 sensor, multispectral images from the Landsat-8 sensor and multispectral images acquired from both instruments. The elaborated scheme is novel in the context of polish complex agricultural structure: compact, narrow parcels and smallholders. The study was conducted to answer the following questions:

Is the time-series classification based on the data from only one sensor sufficient and what level of accuracy does it ensure compared to the multi-sensor classification combined with S-2 and L-8 in the context of the Polish agrarian structure?

- Is the configuration of the crop types to be classified important for the results, and if so, on what level? Is it possible to detect dominant crops only or minority (poorly represented) crops as well?

- How accurately can different crop groups be identified using pixel-based approach? 


\section{METHODS AND MATERIALS}

\subsection{Area description and crop statistics}

The Lublin Upland was chosen to test and perform the experiment. It is a very agricultural area with loess valleys as the dominant geomorphologic forms. Agriculture is well-developed, as fertile mould soil is located there. Crops of wheat, hop and sugar beet dominate in the Lublin Upland. The region is a leading producer of soft fruits. Small individual and private farms dominate in this area, while the number of large-scale farms is non-significant. Compared to other Polish regions, the area of the parcels is rather small ( $<1 \mathrm{ha})$ and farms are fragmented (Figure 1). What should be mentioned here is the distinctive nature of the agrarian structure in Poland, which has an impact on the monitoring of greening practices. There are two main issues: 1. the parcels size and 2. the dominant crop groups. According to the Paying Agency in Poland, the average agricultural parcel size is rather small (approx. $1.5 \mathrm{ha}$ ). The average size of agricultural land in a single farm in Poland is approximately 10 ha and varies from 4 ha to 30 ha or more depending on the province (Notice No. 1, 2019). The area of agricultural land per farm is on the increase, having grown from 9.9 ha to 10.9 ha in the last 10 years. On average, one farm consists of 10 agricultural parcels growing an average of 5 crops (Figure 1). The diversification of crops on the farm is high and the probability of monoculture is fairly low (Krzyżanowski, 2018). It can be expected that the diversification rate will be high. Another vital issue is the dominant kinds of crops making up 95\% of the agricultural land surface. There are 8 main crops, each of which exceeds $1 \%$ of the total agricultural area in Poland. These groups (Table 2) were considered the main crop groups and were used as a basis for crop identification using satellite images. In addition, in the study, a group of less numerous crops (i.e., ecological focus areas) was taken into account under the greenings requirements.
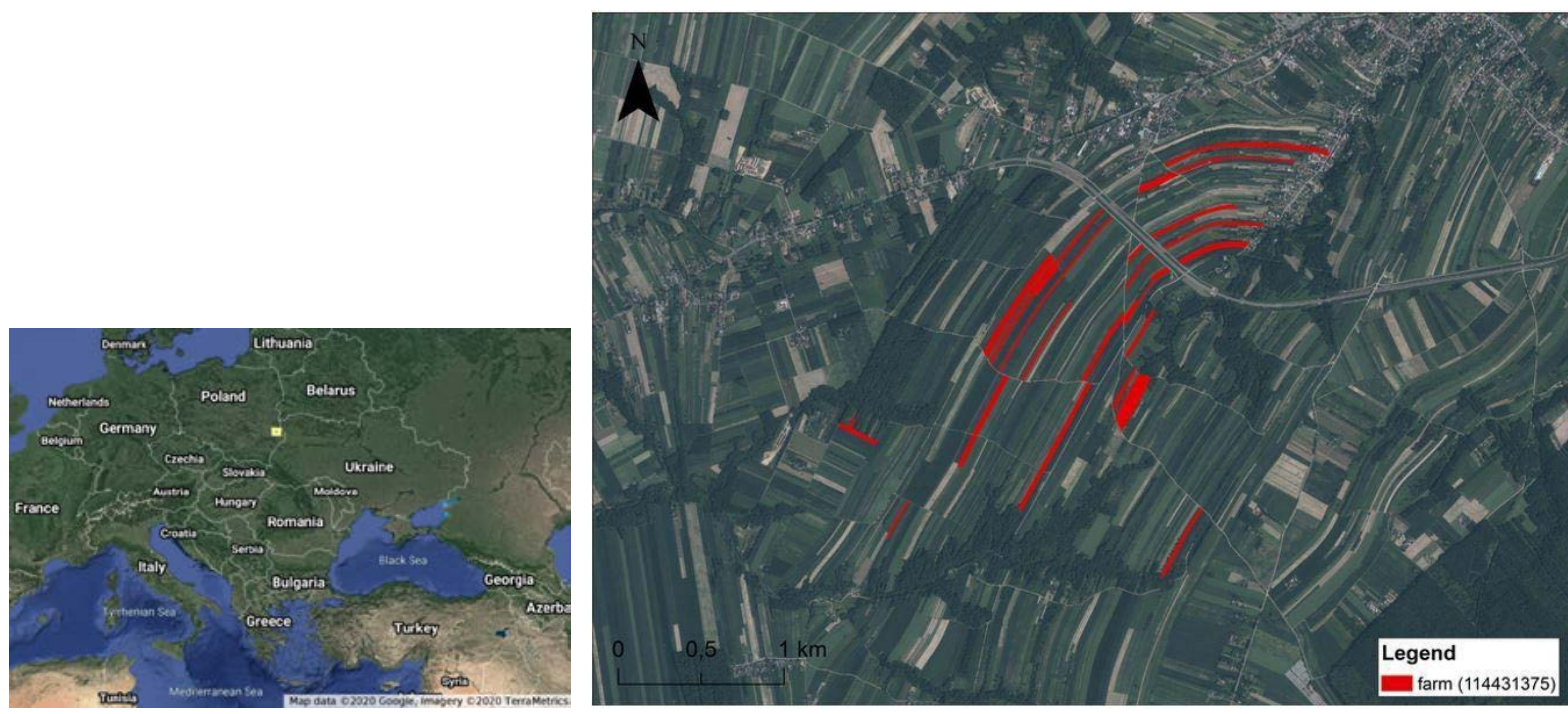

Figure. 1. Example of typical farm and parcels pattern for the study area. In red colour, there are parcels belonging to one farm. On left hand side, the localisation of test area in Poland.

\subsection{Data used in experiments: satellite scenes and LPIS}

Satellite scenes and the Land Parcel Identification System (LPIS) data from 2016 were used to perform the experiment. According to satellite data, Sentinel-2 (Level 1C data, all granules that at least partially cover test areas plus its metadata and cloud masks) and Landsat-8 (OLI, all products that at least partially cover test areas, as a supplementary dataset to Sentinel-2) were used. The images were acquired in 2016, from March to September. Table 1 presents the dates when satellite scenes were acquired referring to the period of the season. All available images 
without cloud cover for this study area were used, 10 images of S2 and 6 images of L8 in total (Table 1).

Table 1. Dataset of S2 and L8 used for classification in correlation with growing stages

\begin{tabular}{|c|c|c|}
\hline Period & S2 scenes dates [2016] & L8 scenes dates [2016] \\
\hline \multirow{8}{*}{ Spring } & & 19.03 \\
\hline & & 2.04 \\
\hline & 19.04 & \\
\hline & 27.04 & \\
\hline & & 4.05 \\
\hline & 10.05 & \\
\hline & 20.05 & \\
\hline & 27.05 & \\
\hline \multirow{4}{*}{ Summer } & & 5.06 \\
\hline & 16.06 & \\
\hline & 29.06 & \\
\hline & 26.07 & \\
\hline \multirow{3}{*}{ Autumn } & & 08.08 \\
\hline & 25.08 & \\
\hline & 04.09 & \\
\hline
\end{tabular}

An LPIS is an information system based on agricultural plots used to control subsidies made under the common agricultural policy. The data kept within LPIS databases concerns the location, geometry and the type of crop, which is declared by farmers. These crop declarations are reference data in vector layers as a whole parcel or part of the parcel. Each crop is associated with the so-called crop dictionary, which serves to define whether a given crop constitutes arable land, permanent grassland, a perennial crop, short rotation coppice or an afforested area. These crops were used to create the so-called crop key (Table 2) to establish test data for training and for classification quality assessment. Nearly 240,000 crop parcels were derived from LPIS (updated during the campaign in 2016) in the test area, whereof more than 30,000 parcels were used in the process of classification (Table 2). LPIS is a system that updates on a regular basis, which allowed to select all the needed parcels automatically using SQL and prepare for tests with any manual intervention. Parcels with the largest acreage for a given crop were used as models for training, with the sum of area, which constituted at least $1 \%$ of the entire crop growing in the test area. The parcels for which the area was not less than 0.5 ha, were used for control and classification assessment. The remaining plots with area less than 0.5 ha were not used in the evaluation. Since acreage of the parcels varies strongly, hence, the imbalance in the numbers of parcels and training area between the particular crops. 
Table 2. The crop types and classes used for Random Forests classification

\begin{tabular}{|c|c|c|c|c|c|c|}
\hline $\begin{array}{l}\text { Crop } \\
\text { group }\end{array}$ & $\begin{array}{l}\text { Greening } \\
\text { practice }\end{array}$ & $\begin{array}{l}\text { Crop name } \\
\text { (by LPIS) }\end{array}$ & $\begin{array}{l}\text { Class } \\
\text { No. }\end{array}$ & $\begin{array}{c}\text { Total } \\
\text { number } \\
\text { of } \\
\text { parcels }\end{array}$ & $\begin{array}{c}\text { Number of } \\
\text { training } \\
\text { parcels }\end{array}$ & $\begin{array}{l}\text { Training areas } \\
\text { [\% of crops } \\
\text { area] }\end{array}$ \\
\hline \multirow{8}{*}{ dominant } & $\begin{array}{c}\text { PG - } \\
\text { permanent } \\
\text { grassland }\end{array}$ & $\begin{array}{l}\text { permanent } \\
\text { grassland }\end{array}$ & 1 & 412 & 15 & 4 \\
\hline & \multirow{6}{*}{$\begin{array}{c}\text { CD - } \\
\text { crop } \\
\text { diversification }\end{array}$} & corn & 2 & 1495 & 15 & 5 \\
\hline & & rapeseed & 3 & 2879 & 26 & 4 \\
\hline & & spring cereals & 4 & 5581 & 58 & 4 \\
\hline & & winter cereals & 5 & 11547 & 53 & 3 \\
\hline & & potatoes & 6 & 120 & 19 & 16 \\
\hline & & beets & 7 & 194 & 19 & 10 \\
\hline & $\begin{array}{l}\text { EFA1 - } \\
\text { fallow land }\end{array}$ & $\begin{array}{l}\text { bare soil, } \\
\text { green cover }\end{array}$ & 8 & 909 & 7 & 20 \\
\hline \multirow{14}{*}{$\begin{array}{c}\text { non- } \\
\text { dominant }\end{array}$} & \multirow{3}{*}{$\begin{array}{l}\text { EFA12 - } \\
\text { short rotation } \\
\text { coppice }\end{array}$} & willow & \multirow{3}{*}{9} & \multirow{3}{*}{5} & \multirow{3}{*}{3} & \multirow{3}{*}{24} \\
\hline & & poplar & & & & \\
\hline & & birch silver & & & & \\
\hline & \multirow{2}{*}{$\begin{array}{c}\text { EFA13 - } \\
\text { wooded area }\end{array}$} & $\begin{array}{c}\text { forest } \\
\text { nurseries }\end{array}$ & \multirow{2}{*}{10} & \multirow{2}{*}{85} & \multirow{2}{*}{6} & \multirow{2}{*}{18} \\
\hline & & $\begin{array}{l}\text { forest on } \\
\text { arable land }\end{array}$ & & & & \\
\hline & \multirow{9}{*}{$\begin{array}{c}\text { EFA15 - } \\
\text { N-fixing crops }\end{array}$} & lupina & 11 & 1666 & 18 & 7 \\
\hline & & faba bean & 12 & 1845 & 15 & 5 \\
\hline & & alfalfa/lucerne & 13 & 933 & 8 & 6 \\
\hline & & pea & 14 & 2357 & 14 & 1 \\
\hline & & lentil & 15 & 3 & 2 & 40 \\
\hline & & clover spp. & 16 & 1396 & 12 & 1 \\
\hline & & soybean & 17 & 1328 & 13 & 5 \\
\hline & & field bean & 18 & 36 & 8 & 6 \\
\hline & & $\begin{array}{l}\text { common birds' } \\
\text { foot }\end{array}$ & 19 & 11 & 6 & 1 \\
\hline & & & sum & 32782 & 314 & 5 \\
\hline
\end{tabular}

\subsection{Methods of data processing}

\subsubsection{Crops and class setting}

Crops used in the study have a total area of $94 \%$ of all the agriculture parcels (based on LPIS data). The remaining area (6\%) is covered by minor crops (e.g., vegetables) occurring on small and scattered plots, which are excluded from the classification process. The statistics from LPIS show a wide diversity in parcel areas, which has an essential impact on the level of difficulty in 
classification implementations. It was decided to apply common multitemporal classification for all the crops as a single strategy. For this purpose, different Random Forests approaches were employed using various training datasets. This study used dominant crops for the research area such as permanent grassland (PG), rapeseed, winter and spring cereals, beetroots, maize, potatoes and fallow land. All EFAs such as EFA1 (fallow land), EFA12 (short rotation coppice), EFA13 (wooded area) and EFA15 (N-fixing crops) as separate classes were also considered in the detection process. The final crop types with statistics are presented in Table 2. Since different crops have different representation in the field, the training areas vary from $1 \%$ to $16 \%$ of particular crop area. There are a few exemptions, that is, EFA1, EFA12, EFA13 and EFA15 (lentil) where training areas vary between $18 \%$ and $40 \%$. The reason is the limitation in parcel numbers and difficulties with finding a good representation. EFA1 - a lot of small parcels (sometimes with green cover), EFA12 - not very popular, EFA13 - narrow and elongated parcels (1-20 m width) along the edge of the forest. EFA15 - N-fixing crops are 26 species on the list (of Paying Agency) and only a few occur in the study area. Moreover, EFA15 are not only specific species but crop mixtures as well.

The vector data constituting training areas refer to parcel borders with a surface area ranging from 0.5 ha (majority) to the largest crop area of up to 20 ha (just a few within the research area). For the training stage, around $1 \%$ of parcels were used, but no more than 250 ha for each crop. Using SQL, around 50-60 parcels with the largest area were selected but with limitation of the minimum area at 0.5 ha level. Hence, some crops (e.g., class no. 8, 9, 10) are not well represented by parcel numbers. As a result, the following two vector datasets were obtained:

1. for dominant crops, that is, permanent grassland (class no. 1), 6 main crops (classes no. 2-7) and fallow land (class no. 8); in total 8 classes;

2. for minority crops, that is, EFA12 (class no. 9), EFA13 (class no. 10) and EFA15 (classes no. 11-19) giving 11 classes in total.

These two sets constituted input training data to the model: as two separate sets of crops (8 or 11 classes) and as one training set for all the crops (19 classes), and were used for different classification options on images acquired by L8 and S2. Because of the heterogeneity of border pixels, the reduction of parcel area (polygon) was implemented using an inner buffer of $10 \mathrm{~m}$ (the size of 1 pixel) set aside from the external border. This procedure was not applicable to EFA classes as the size of many parcels for these classes was too narrow (originally 2-3 pixel size). Finally, 16 variants of classification were performed (Table 3), including per-pixel and per-parcel validation approaches. 
Table 3. Performed variants of RF classification and validation, where: pix - pixel-based validation, parcel - per-parcel validation approach

\begin{tabular}{|c|c|c|c|}
\hline Variant & Satellite & Classes set & Approach for validation \\
\hline 1. & S2 & 19 classes & pix \\
\hline 2. & S2 & 19 classes & parcel \\
\hline 3. & S2 & 8 classes & pix \\
\hline 4. & S2 & 8 classes & parcel \\
\hline 5. & L8 & 19 classes & pix \\
\hline 6. & L8 & 19 classes & parcel \\
\hline 7. & L8 & 8 classes & pix \\
\hline 8. & L8 & 8 classes & parcel \\
\hline 9. & L8 & $11($ EFA) classes & pix \\
\hline 10. & L8 & $11($ EFA) classes & parcel \\
\hline 11. & S2+L8 & 19 classes & pix \\
\hline 12. & S2+L8 & 19 classes & parcel \\
\hline 13. & S2+L8 & 8 classes & pix \\
\hline 14. & S2+L8 & 8 classes & parcel \\
\hline 15. & S2+L8 & $11($ EFA) classes & pix \\
\hline 16. & S2+L8 & $11($ EFA) classes & parcel \\
\hline
\end{tabular}

\subsubsection{Random Forests algorithm and data processing}

A literature review (see section 2) and preliminary tests helped to consider and finally to select the most appropriate method of classification. The Random Forests (RF) classifier is one of the machine learning approaches in remote sensing image processing and it was chosen to perform crops classification in this study. The RF classifier can be used to obtain spatial information on crops represented by the variation of training data ensuring a high quality of results (Inglada et al., 2015; Inglada et al., 2016; Shelestov et al., 2017). Random Forests algorithm (Breiman, Cutler, 2019) implemented in En-MAP Box software (van der Linden et al., 2015) has been used. RF is a fast and stable algorithm for a considerable dataset to be classified and is insensitive to a small and diverse number of samples for large sets of data for classification (Belgiu, Dragut, 2016). It was also one of the reasons to choose RF as an algorithm for classification. It was used in this study to perform time-series crops classification based on Landsat-8 (L8) and Sentinel-2 (S2) data in different variants (Table 3). In order to get reliable spatial information for crop diversification in a fragmented parcel area, fine spatial resolution data was used with 10-20 m pixel size obtained from the Sentinel-2 platform (10 bands: B02B08, B08a, B11, B12) and from Landsat-8 (6 bands: 2-7 and 1 panchromatic). The images from both S2 and L8 sensors were subjected to pre-processing including atmospheric correction, reflectance calculation and sharpening to $10 \mathrm{~m}$ pixel size of Sentinel-2 and $15 \mathrm{~m}$ of Landsat-8. Next, all the resample bands were stacked into single (multitemporal and multilayer) files consisting of 100 layers for Sentinel-2, 30 layers for Landsat-8 and 130 layers for S2 and L8 together. Subsequently, the RF classifier implemented in En-MAP Box software was run using prepared training datasets. Results of the RF classification process include a model for decision tree parameterization, an analysis of variable importance and a raster image as the output. The classification parameters are as follows: class numbers $-\mathrm{n}(\mathrm{n}=19,8$ or 9$)$, training areas - at least 1 for each class, numbers of trees - 100, numbers of features - square root of all 
features, impurity function - Gini Coefficient, minimum number of samples in node -1 , minimum impurity -0.00 . The next stage involved image post-processing including majority filtration giving pixel-crop map and zonal statistics for the dominant class value within a single parcel resulting in a parcel-crop map. Following statistical validation, the results were assessed using the control dataset derived from the LPIS (Figure 2).

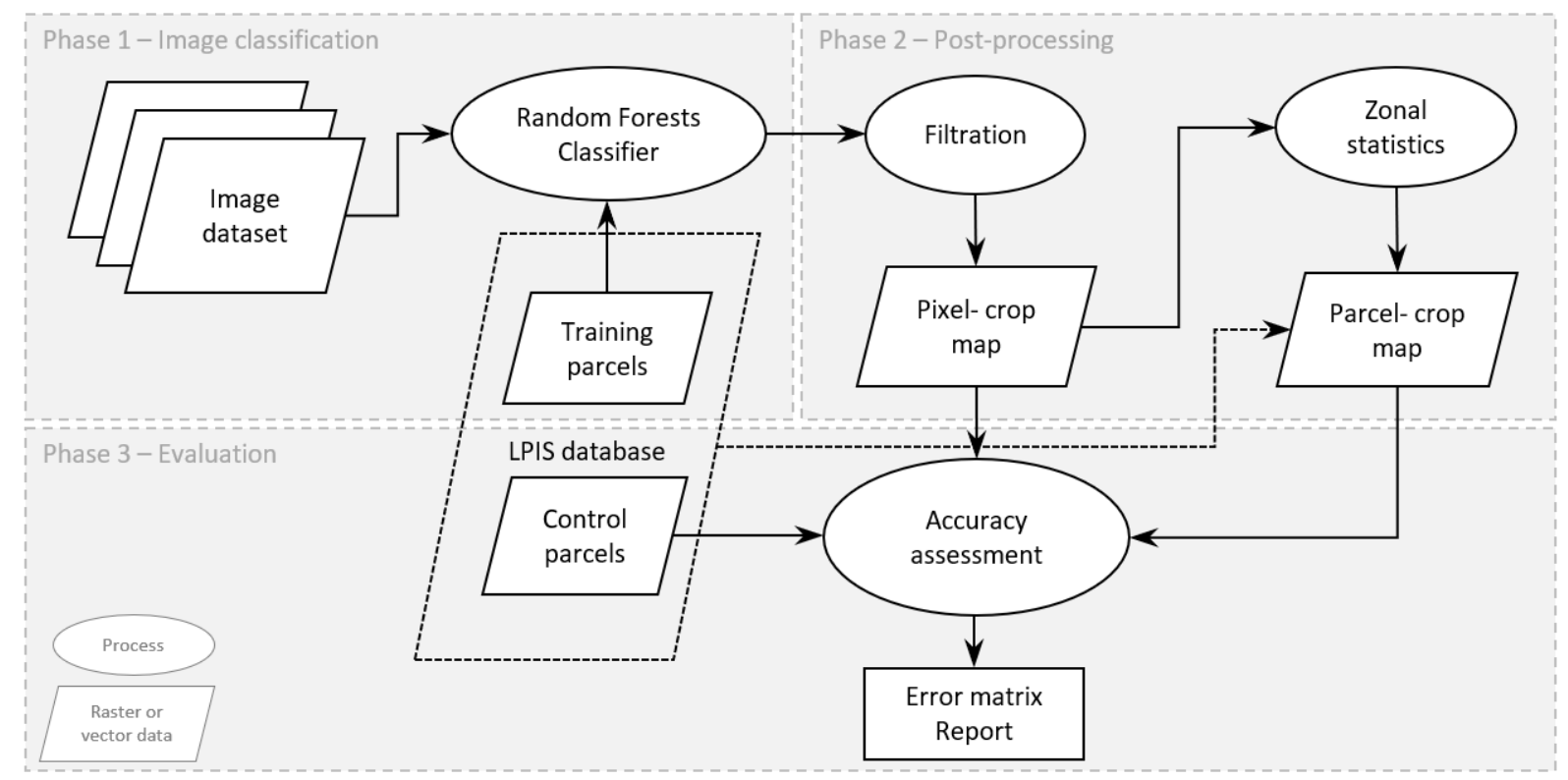

Figure 2. Scheme of RF classification and evaluation

The spatial distribution of crops was evaluated using the methodology adopted from literature (Congalton, Green, 2009). Both approaches (per-pixel and per-parcel) in each variant of classification were assessed using the following statistical parameters: CE (commission errors), OE (omission errors), PA (producer's accuracy), UA (user's accuracy) and the general parameters OA (overall accuracy, $\Omega$ - omega), F1 and K (kappa). The interpretation of these parameters, their formula and usability are described in Congalton and Green (2009) and Lillesand et al. (2014). The UA coefficient indicates the probability of a pixel classified into a given category actually representing that category on the ground. Consequently, it accurately describes the possibility of correct crop recognition in the fields. The PA measure indicates how well training set pixels are classified. F1 is a weighted harmonic mean of User Accuracy and Producer Accuracy for each class. The OA parameter describes the best overall accuracy of a particular classification. It is a percentage of correctly classified pixels. This value is the most commonly reported accuracy assessment statistic and accurately describes the classification result itself. The Kappa value is a measure of agreement between classification and the reference data. This is why this measure is a good parameter to compare different classification results. These statistics were used to describe and compare the results in the next section.

\section{RESULTS}

The best results were achieved for the set of Sentinel-2 and Landsat- 8 used in one common classification for 8 dominant crops where the overall accuracy was almost $91 \%$ and kappa was over $85 \%$. The overall accuracy for this variant was more than $5 \%$ higher than for S2 (only) and more than $12 \%$ higher than for L8 (only). For 19 classes in the per-pixel approach, there is no significant difference between S2 $(\mathrm{OA}=72 \%)$ and S2+L8 $(\mathrm{OA}=73 \%)$ results. However, the overall accuracy was $12 \%$ higher for $\mathrm{L} 8+\mathrm{S} 2(\mathrm{OA}=89 \%)$ in the parcel-based approach than for $\mathrm{S} 2$ as a single set of images. An example of the classified image as a map is shown in Figure 
3. This image is a variant of Sentinel-2 and Landsat-8 common classification for 19 classes aggregated into crop groups. Next sections show more details on the results achieved in the designed approaches.

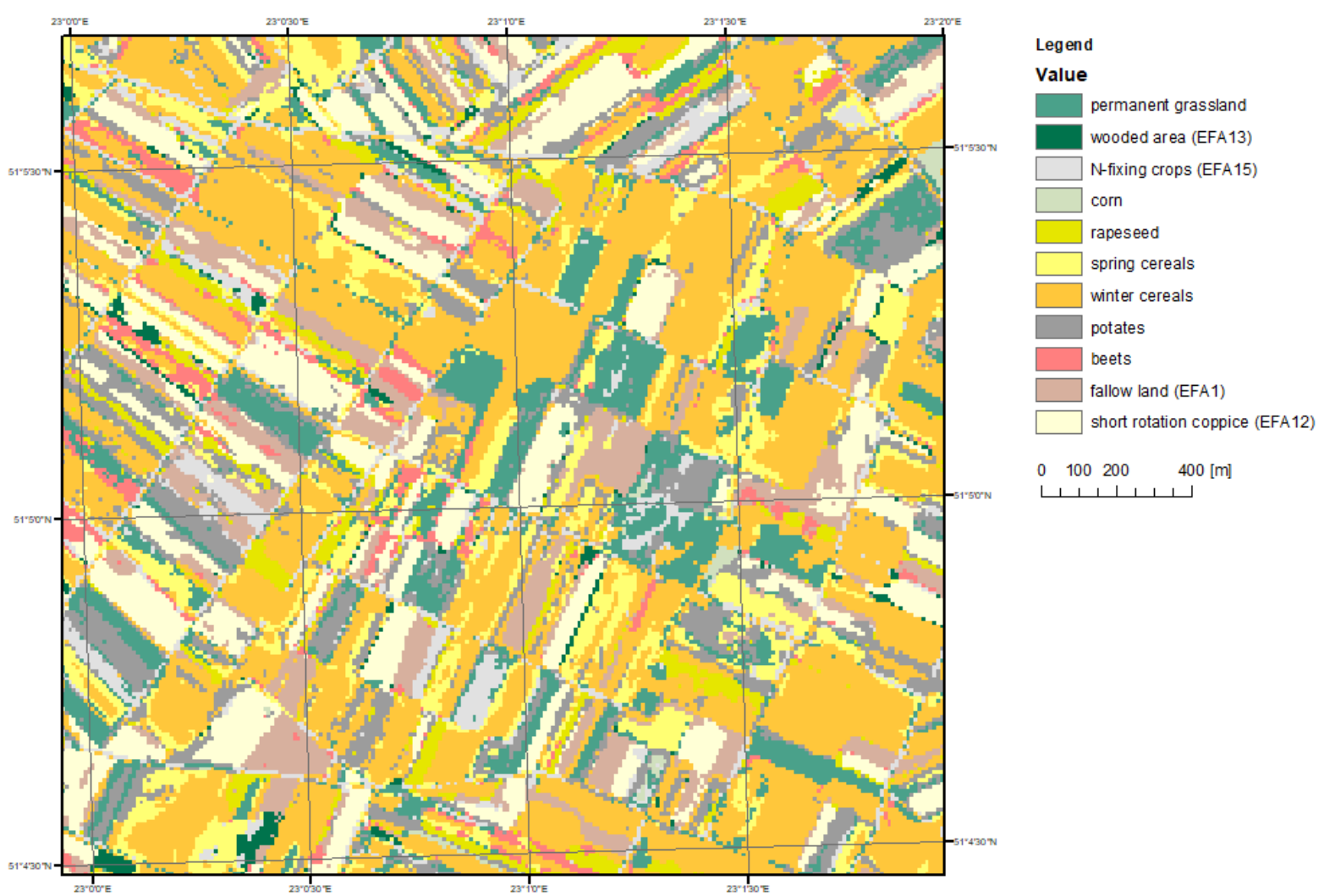

Figure 3. An example of RF classification result - variant of Sentinel-2 and Landsat-8 classification for 19 classes aggregated to crop groups

\subsection{Results for Sentinel-2}

Overall accuracy for 19 classes is $72 \%$ for the per-pixel approach and $77 \%$ for the per-parcel variant slightly higher. Low OA values are due to the poor results for non-dominant crops (all EFAs), permanent grassland and fallow land, which is further discussed in detail. Most of the dominant crops, that is, cereals, corn and rapeseed, produced results with UA ranging from 80 to over $89 \%$ for the per-pixel approach and from 83 to $93 \%$ for the per-parcel variant. In regards to potatoes and beets, even though they belong to the dominant group, their results are not satisfactory. Within the minority crops group, only short rotation coppice (F1 $=88 \%$ ) and wooded area $(\mathrm{F} 1=72 \%)$ in the per-parcel approach yielded considerable results.

A better result was achieved for 8-class classification (Figure 4 ) with $\mathrm{OA}=82 \%$ in the perpixel and $\mathrm{OA}=85 \%$ in the per-parcel validation. Again, crops such as corn, rapeseed and cereals produced results with F1 ranging from $77-87 \%$ for the per-pixel and to $81-89 \%$ for the per-parcel variant. A similar situation as in 19-class classification with low accuracy occurred for fallow land, permanent grassland, potatoes and beets. Their indicators (UA, PA) are slightly higher (by a marginal percentage) in per-parcel classification, but fallow land disappeared entirely after aggregation. This class usually went to the permanent grassland class if it was green cover. The low results for potatoes and beets probably come from very narrow parcels. 

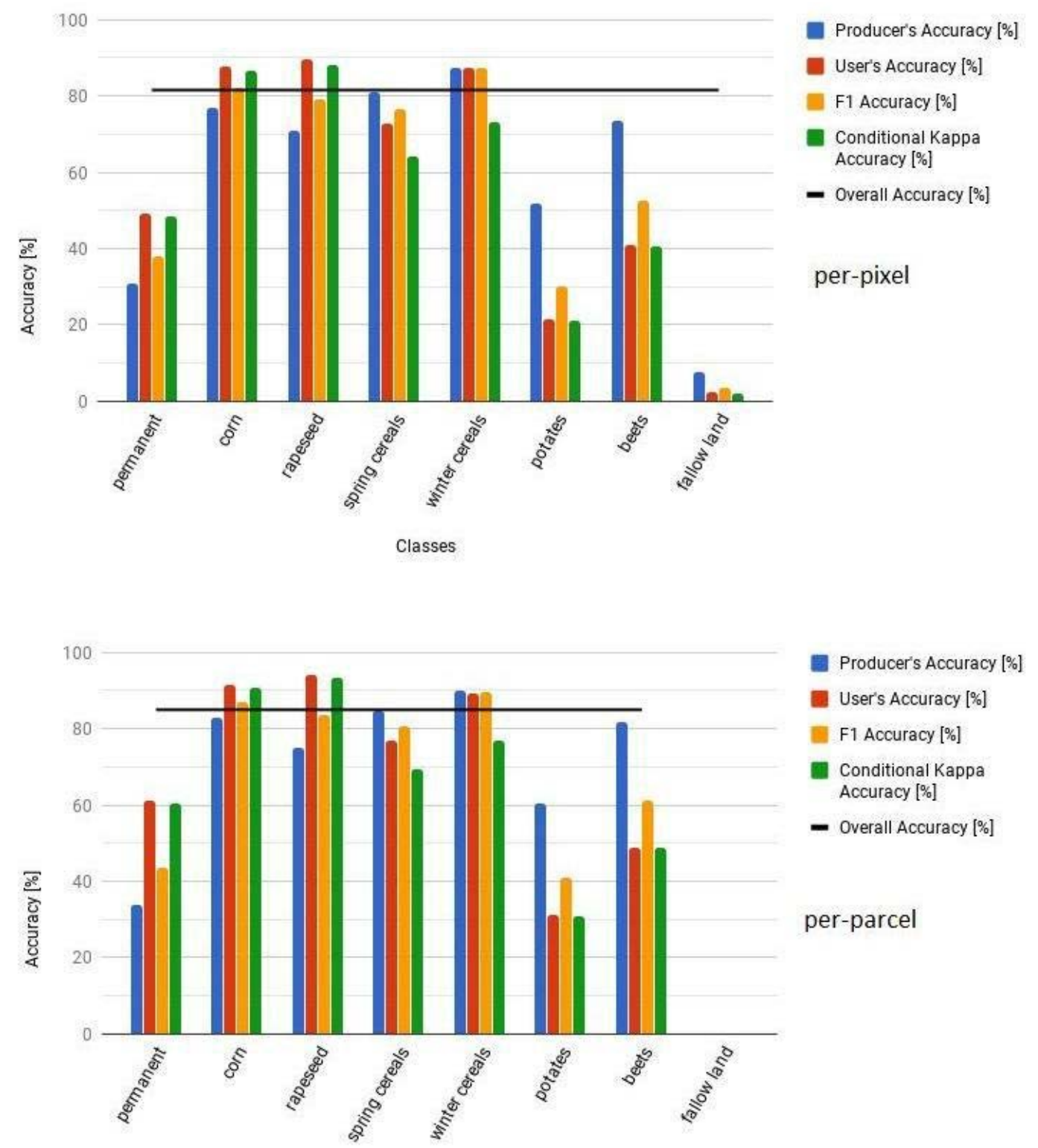

Classes

Figure 4. Results of Sentinel-2 pixel-based (variant no. 3) and parcel-based classification for only dominant 8 classes (variant no. 4)

\subsection{Results for Landsat-8}

According to Landsat-8 classification, better results were achieved for the parcel-based approach, that is, after aggregation into parcels. For the 19-class parcel-based approach (variant no. 6), the overall accuracy $(\mathrm{OA}=84 \%)$ was more than $20 \%$ higher than for the pixel-based approach (variant no. 5). Additionally, the results of the parcel-based approach yielded values of the producer's, user's and F1 accuracy rates higher and more homogeneous for non-dominant crops. In both approaches, wooded area, corn and winter cereals were classified accurately, but the indices for fallow land and potatoes remained low.

For the variant with 8 dominant crops, the overall accuracy was approximately $12 \%$ higher for the parcel-based approach $(\mathrm{OA}=78 \%)$ than for the pixel-based approach $(\mathrm{OA}=66 \%)$. According to the pixel-based approach's outcome, the lowest accuracy is recorded in potatoes, 
beets and fallow land, and likewise for Sentinel-2. The results obtained for permanent grassland were not satisfactory either. Consequently, similar results were obtained for parcel-based classification (Figure 5). It should also be highlighted that category EFA1 is bare soil and green cover in one class, since there is no differentiation between these two categories within the LPIS. Therefore, the selection of the training and control sets from the database in a fully automatic way without additional intervention resulted in low quality classification.

Another observation is a significant difference between accuracies at pixel level and parcel level, while in the case of Sentinel-2, there is no such effect. Probably the main reason is the spatial resolution of $30 \mathrm{~m}$ for Landsat-8, which in comparison to the small-sized parcels is too large to give proper information about the crop. The aggregation in this case raises accuracy. The second reason is a time-series, which is not so dense as Sentinel-2; therefore, it is reasonable to consider the combination of both sensors.

For variants with EFAs crops only, the overall accuracy of classification was slightly higher than $25 \%$. The highest accuracy was for lupine, where F1 $=40 \%$ and the other minority crops results (EFA1, 12, 13, 15) were too low to be considered as satisfactory. There are two reasons for this, namely the rarity and small area of these crops (often below $0.5 \mathrm{ha}$ ), which explains why only a few samples were eligible for training and control phases. 

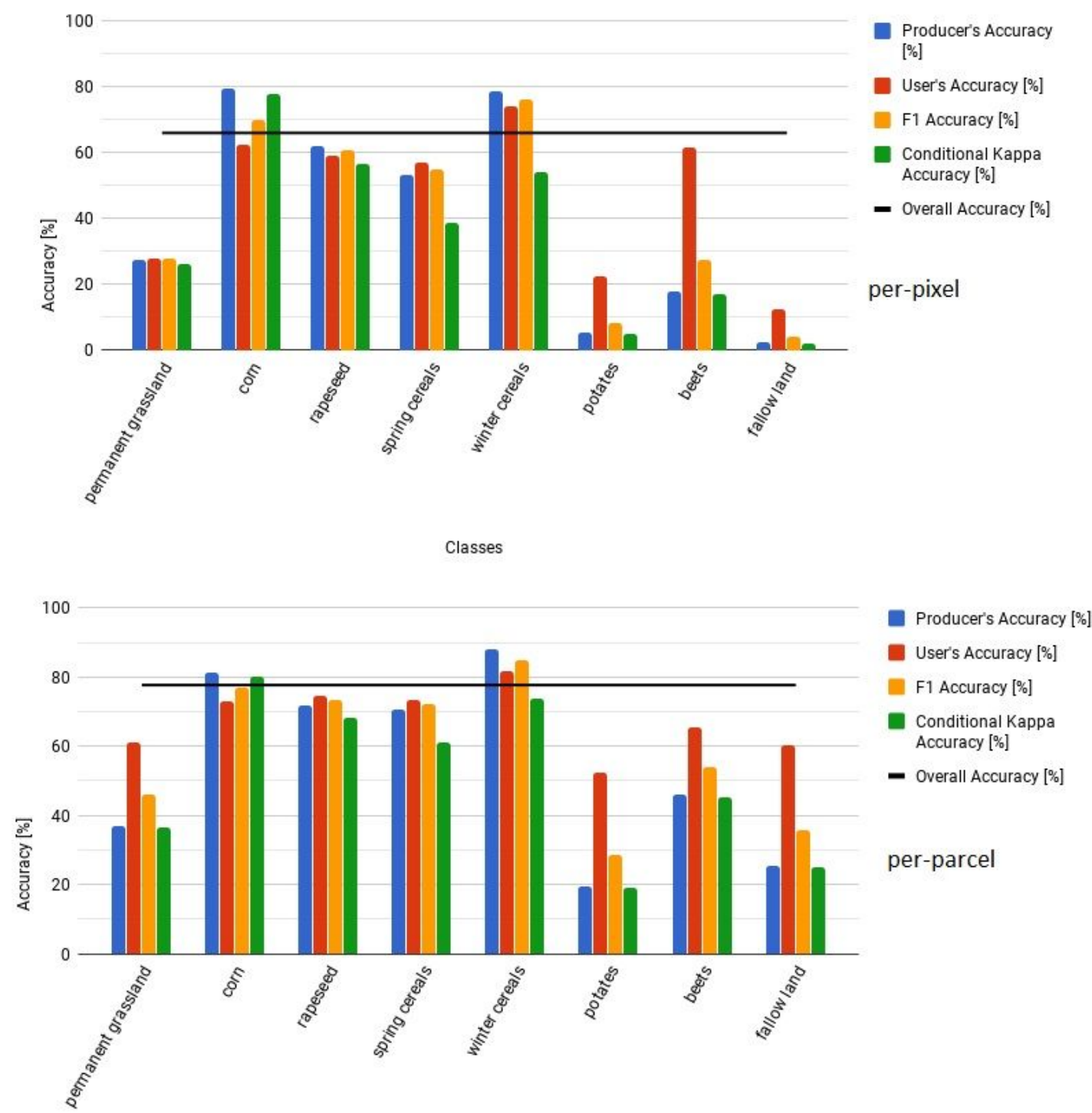

Classes

Figure 5. Results of Landsat-8 pixel-based (variant no. 7) and parcel-based (variant no. 8) classification for 8 classes

\subsection{Results for Sentinel-2 and Landsat-8 combined}

For 19 classes, $\mathrm{OA}=73 \%$ for the per-pixel and 89\% for the per-parcel approach. In the pixelbased map, the highest accuracy is for corn, rapeseed, spring and winter cereals with F1 ranging from $68 \%$ to $85 \%$. The same crops in per-parcel variant achieved F1 ranging from $87 \%$ for corn to $95 \%$ for winter cereals. The lowest classification accuracy was obtained for lupine, pea and fallow land. For EFA crops, similar to previous classifications, the results with OA $=22 \%$ are not satisfactory. The highest result for alfalfa with F1 is slightly above $40 \%$. The most confusion is within a common group of nitrogen-fixing crops (i.e., lupine, alfalfa, pea, etc.), so altogether such crop types constitute one group of EFA15 achieving OA > 90\% with Kappa < $20 \%$. This means high accuracy for the whole class (EFA15) with confusion between particular $\mathrm{N}$-fixing crops themselves. Therefore, it is possible to identify EFA15 as a whole group but not particular $\mathrm{N}$-fixing crop type. Comparing the results obtained from a single sensor (Sentinel-2, Landsat-8) and two sensors combined (Landsat-8 + Sentinel-2), one can say that the classification using satellite scenes from two different systems produces better results. They complement each other with temporal-spectral information on crops. 
For 8 dominant crops, $\mathrm{OA}=82 \%$ in the per-pixel and $\mathrm{OA}=91 \%$ in the per-parcel variant. The results are presented in Figure 6 . The best results were achieved by the following crops: corn $\mathrm{UA}=86 \%$, rapeseed UA $=87 \%$, spring cereals $\mathrm{UA}=90 \%$ and winter cereals UA $=94 \%$. Potatoes UA $=75 \%$ and permanent grassland UA $=74 \%$ were classified with the lowest rate. The last result (PG) is rather surprising, likewise for earlier L8 and S2 single-sensor classifications. Permanent grassland are confused mostly with winter cereals in 8-classes classification or with $\mathrm{N}$-fixing crops (i.e., lucerne, clover) in 19-classes process. It is probably caused by changes made by farmers on parcels, agrotechnical treatments or their improper crop declarations. Otherwise, considering the period from March (19.03) to September (04.09), it is not long and dense enough in image (values) representations to properly differentiate spectrally these classes.

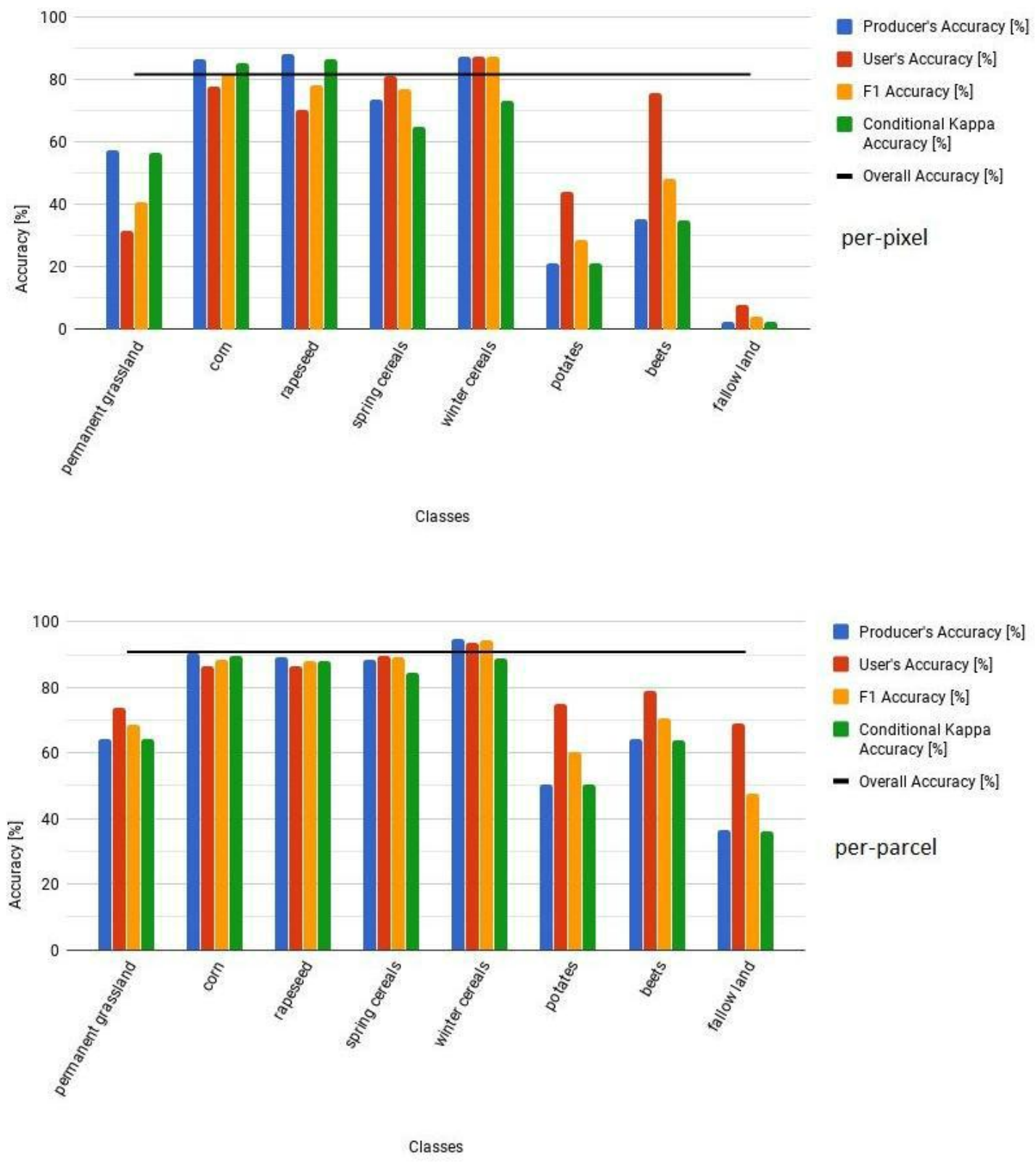

Figure 6. Results of Landsat-8 and Sentinel-2 pixel-based classification (variant no. 13) and parcel-based classification (variant no. 14) for 8 dominant classes 


\section{DISCUSSION}

For 19 classes in the per-pixel map, there is no statistically significant difference between S2 $(\mathrm{OA}=72 \%)$ and $\mathrm{S} 2+\mathrm{L} 8(\mathrm{OA}=73 \%)$ results. However, the overall accuracy was $12 \%$ higher for $\mathrm{L} 8+\mathrm{S} 2(\mathrm{OA}=89 \%)$ in the parcel-based approach than for S2 as single sensor images. Some of the crop types such as EFA15 (N-fixing crops) show a similarity of temporal and spectral characteristics, therefore, they are confused in the classification process, producing low results. It was impossible to detect such crops individually, although they separated from other crop groups fairly well.

For 8 dominant crops variants, the best results were achieved for the combined scenes S2+L8 in the parcel-based map, where the overall accuracy was almost $91 \%$ and kappa over $85 \%$. The overall accuracy was more than 5\% higher than for S2 and more than $12 \%$ higher than for L8 (Figure 7).

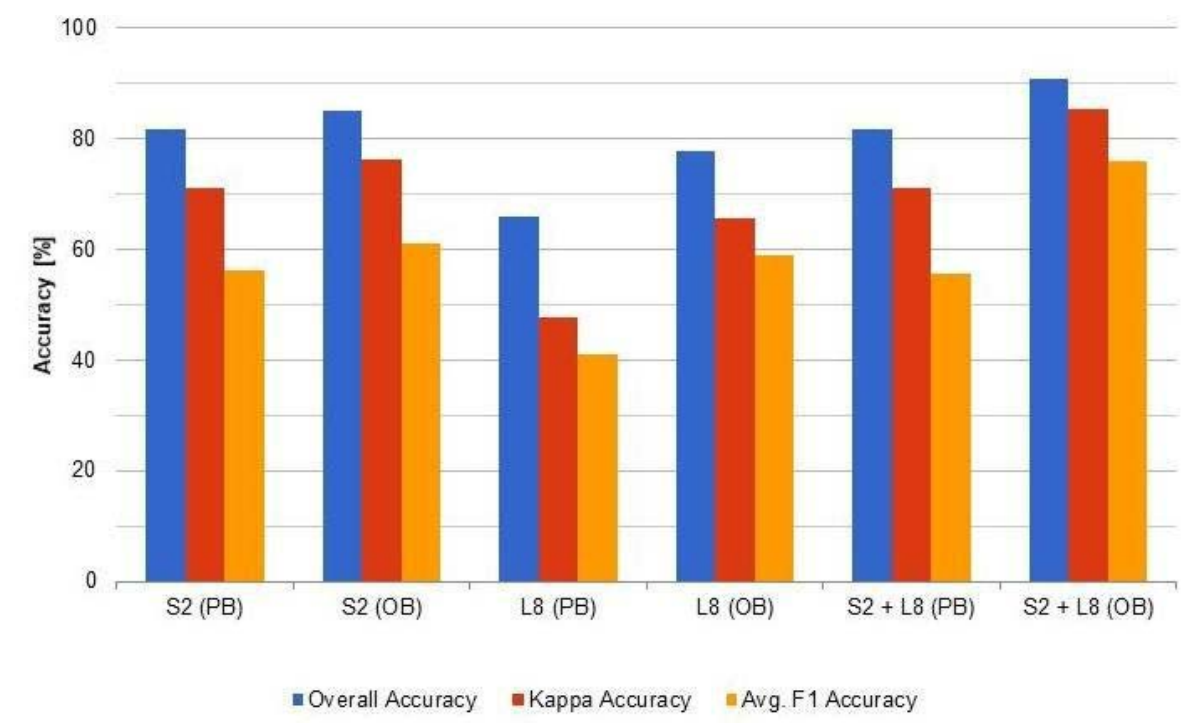

Figure 7. Comparison of 8 dominant classes results for Sentinel 2 and Landsat 8 (PB - pixel-based validation, OB - parcel-based validation)

The parcel data from the LPIS used for training as references and for control of the results should be selected automatically based on the crop type, area and homogeneity within the parcel, without manual interventions. However, in the case of fallow land and permanent grassland, this automatic approach is limited. This is due to the lack of details in farmers' declarations in case of permanent grassland treatment (i.e., cutting or ploughing date) and appeared temporary as black cover. Permanent grassland and fallow land is not always covered by grass throughout the year. Due to the fact of different agrarian treatments and inaccurate declaration in LPIS, these two classes are confused among themselves or even sometimes with mix grass on arable land.

The next class, that is, fallow land, encountered a problem with detection within the classification process as well. The definition of fallow land as black or green cover in the LPIS (Figure 8) cause an impossibility of separation as mono-class in SQL from the LPIS database. There are two types of covers: green and black within one class declared as fallow land. In case fallow land is a black cover, it is separated from other classes, in case fallow land is a green cover, it is confused with permanent grassland. This makes it impossible to build a consistent sample in the training phase in a fully automatic way. To make a proper classification for this class, it is recommended to keep black or green fallow indicators in LPIS records. 


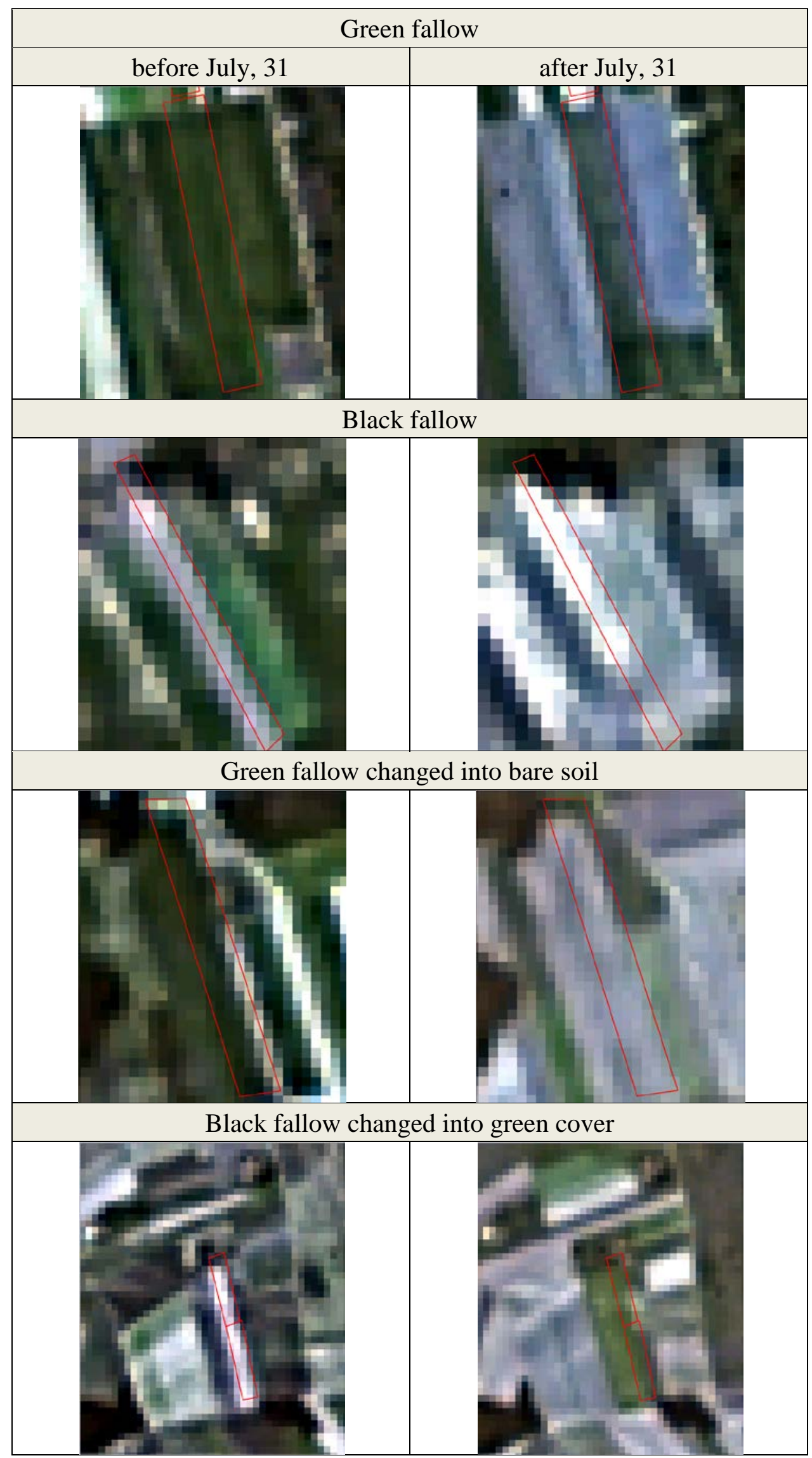

Figure 8. Examples of green fallow and black fallow during the year 
There is a small difference between the training sets defining crop type classes; accuracy achieved for 8 classes was slightly (2-3\%) higher than for 19 classes (dominant crops, permanent grassland and EFAs). The separation for dominant crops - 8 classes, and minority crops - 9 classes (such as EFAs) is recommended, but one cannot expect a significant improvement of results. The inclusion of rare classes such as $\mathrm{N}$-fixing crops (variants with 19 classes) does not affect the accuracy of dominant crop classification (a decrease by a few per cent). Random forests, even if addressed for classification with a small number of training fields, does not produce good results for such crops, which was shown within the classification for the EFAs group.

In general, better results were achieved using per-parcel in post-processing classification. The dominant classes such as corn, rapeseed, winter and spring cereals are well distinguished from others. Potatoes and beets were confused but can be recognized at least as one group of crops. Comparing obtained results with the presented references, Overall Accuracy (OA) is at a similar level. According to Schmedtmann and Campagnolo (Schmedtmann et al., 2015), where Landsat 7 ETM+ multitemporal data were used, the OA was $84 \%$. In the study presented in this article, the OA with the use of Landsat 8 data was the same and comparable with OA presented in Kussul et al. (2015b). In Immitzer et al. (2016), crop classification with the use of Sentinel-2 data was performed and the OA in pixel-based map was $83.2 \%$ and was higher than in the parcel-based map. In the presented results, the OA in pixel- and parcel-based approach is similar (82\% and 85\%) and comparable with results obtained in Immitzer et al. (2016). In Valero et al. (2016), the results for different areas are presented (Table 4), where the achieved OA depends on the region and its agricultural characteristics. Overall accuracy of the classification in central or west Europe (Valero et al., 2016) is slightly higher (e.g., Belgium, Ukraine: 95\%) than in the presented results.

Table 4. Average Overall Accuracy (OA) of crop identification using Random Forests algorithm. Smallholdings region indicated as bold

\begin{tabular}{|c|c|c|c|}
\hline Sensor & OA [\%] & Country & Source \\
\hline \multirow{5}{*}{ Landsat 8/SPOT4 } & 90 & Argentina & \\
& 90 & France & \\
& 92 & Belgium & \\
& 91 & South Africa & Inglada et al., 2015 \\
& 93 & USA & \\
\hline \multirow{5}{*}{ Sentinel2 } & 74 & China & \\
& 80 & Mkraine & \\
\cline { 2 - 5 } & $\mathbf{8 3}$ & Austria & Lambert, 2018 \\
\cline { 2 - 5 } & $\mathbf{8 9}$ & Spain & Sitokonstantinou at al. 2018 \\
\hline & $\mathbf{8 7 - 9 0}$ & Germany & Stefanski, 2013 \\
& $\mathbf{8 6 - 8 8}$ & Luxemburg & \\
\cline { 2 - 5 } SPOT5/RapidEye & $77-94$ & France & \\
& $92-95$ & Belgium & Valero et al. 2016 \\
& $85-95$ & Ukraine & \\
\hline & $55-74$ & Pakistan & \\
\hline
\end{tabular}


Also, the study performed in Spain (Sitokonstantinou et al., 2018) for small holdings showed very similar findings using S2 and L8 data. Overall accuracy given as Kappa for Random Forests algorithm reached 0.78 for crop types and 0.89 for crop families. The best classification quality (UA) was indicated for rapeseed (95\%) and corn (93\%), while the worst for grass (77\%) likewise in our study. Table 5 summarizes the results for the Random Forests algorithm described in the above-mentioned studies.

\section{CONCLUSIONS}

Taking analysis and questions raised in this research, it can be noticed that the multisensor classification based on S-2 and L-8 achieved higher accuracy compared to single-sensor classification with an average level of $5 \%$ to $12 \%$. For 19 classes in the per-pixel approach, there is no significant difference between $\mathrm{S} 2(\mathrm{OA}=72 \%)$ and $\mathrm{S} 2+\mathrm{L} 8(\mathrm{OA}=73 \%)$ results. But the overall accuracy was $89 \%$ for L8+S2 in the parcel-based map. For 8 dominant crops variants, the best results were achieved for the combined scenes S2+L8 in the parcel-based approach, where the overall accuracy was almost $91 \%$. The images from both sensors can be combined in a single scheme of processing.

Higher classification accuracy was achieved using per-parcel in post-processing classification. Moreover, different crop groups can be identified with different accuracy. The dominant crops like corn, rapeseed, spring and winter cereals are well distinguished from others and reached User Accuracy at $86 \%$ to $94 \%$, potatoes and permanent grassland achieved User Accuracy of $75 \%$ on average. Despite the lower accuracy result for permanent grassland, this method can be considered as the method for detecting changes on PG or improper declarations. The minority crops like N-fixing crops or short rotation coppice reached hardly $40 \%$ of accuracy. Therefore, the elaborated and tested methods work well and can be recommended for dominant crop identification, except permanent grassland. In the future, more investigation should be focused on other minority crop types as well.

The assumption of the developed and tested methodology was to include as many crops as possible in one coherent multi-temporal classification process. This was done to simplify and standardize the crop identification process including selected EFA and permanent grassland, treating them as crop types. However, the low representation of plots for EFA12, EFA13 and spectral similarity of crops from the EFA15 group and not always correctly declared permanent grassland caused that the proposed method for these particular crops could not be fully verified in the established research area.

Acknowledgments: Authors acknowledge the Copernicus Open Access Hub and the USGS for providing free access to Sentinel-2 MSI and Landsat-8 OLI images, correspondingly. We are also grateful to ARMA for LPIS data and to WIZIPISI for data collection and pre-processing. Authors thank for allowing the use of EnMapBox and SNAP software as well.

Funding: The research work was carried out as part of the CheckGREEN project run by WIZIPISI - The Wroclaw Institute of Spatial Information and Artificial Intelligence (Ltd.) and NEWIND and was funded by the European Space Agency (ESA). The publishing is funded in the frame of statutory works of Warsaw University of Technology.

Author Contributions: conceptualization, methodology, investigation, supervision and analysis JPK, data processing and validation JPK, PB, MP, writing - original draft preparation JPK, writing - editing MP, PB.

Conflicts of Interest: No potential conflict of interest was reported by the authors. 


\section{REFERENCES}

Asgarian, A., Soffianian A., Pourmanafi S. (2016) Crop type mapping in a highly fragmented and heterogeneous agricultural landscape: A case of central Iran using multi-temporal Landsat 8 imagery. Computers and Electronics in Agriculture, 127, 531-540. https://doi.org/10.1016/j.compag.2016.07.019.

Belgiu, M., Dragut, L. (2016) Random forest in remote sensing: A review of applications and future directions. ISPRS Journal of Photogrammetry and Remote Sensing, 114, 24-31. https://doi.org/10.1016/j.isprsjprs.2016.01.011.

Bontemps S., Bajec K., Cara C., Defourny P., De Vendictis L., Heymans D., Kucera L., Malcorps P., Milcinski G., Nicola L., Slacikova J., Taymans M., Tutunaru F., Udroiu C. (2020) Sen4CAP - Sentinels for Common Agricultural Policy. System Software User Manual. Sen4CAP_SUM_v1.2. ESA (access in December, 2020).

Breiman L., Cutler A. (2019) Random Forests. Available online: https://www.stat.berkeley.edu/ breiman/RandomForests/ (accessed on 16 July 2019).

Commission Implementing Regulation (EU) No 641/2014 of 16 June 2014.

Congalton, G. R., Green, K. (2009) Assessing the Accuracy of Remotely Sensed Data: Principles and Practices, 2nd ed. CRC Press, Taylor \& Francis Group, Boca Raton.

Devos, W., Fasbender, D., Lemoine, G., Loudjani, P., Milenov, P., Wirnhardt, C. (2017) Discussion Document on the Introduction of Monitoring to Substitute OTSC, Technical Report, European Commission: Brussels, Belgium, ISBN 978-92-79-74279-8.

EU SCAR AKIS (2019), Preparing for Future AKIS in Europe. Brussels, European Commission.

Foerester, S., Kaden, K., Foerester, M., Itzerott, S. (2012) Crop type mapping using spectraltemporal profiles and phenological information. Computer and Electronics in Agriculture, 89, 30-40. https://doi.org/10.1016/j.compag.2012.07.015.

Grabska E. (2017) Ocena możliwości wykorzystania satelitarnych danych optycznych i radarowych do identyfikacji typów użytków rolnych [Evaluation of the possibility of using optical and radar satellite data to identify types of agricultural land]. Prace Geograficzne, 148, 135-155.

Ianninia, L., Molijn, R. A., Hanssen, R. F. (2013) Integration of multispectral and C-band SAR data for crop classification. Remote Sensing for Agriculture, Ecosystems, and Hydrology XV p. 88871D. https://doi.org/10.1117/12.2029330.

Immitzer, M., Vuolo, F., Atzberger, C. (2016) First Experience with Sentinel-2 Data for Crop and tree Classifications in Central Europe. Remote Sensing, 8(3), 166. https://doi.org/10.3390/rs8030166.

Inglada, J., Arias, M., Tardy, B., Hagolle, O., Valero, S., Morin, D., Dedieu, G., Sepulcre, G., Bontemps, S., Defourny, P., Koetz, B. (2015) Assessment of an Operational System for Crop Type Map Production Using High Temporal and Spatial Resolution Satellite Optical Imagery. Remote Sensing, 7, 12356-12379. https://doi.org/10.3390/rs70912356.

Inglada, J., Vincent, A., Arias, M., Marais-Sicre, C. (2016) Improved Early Crop Type Identification by Joint Use of High Temporal Resolution SAR and Optical Image Time Series. Remote Sensing, 8(5), 362. https://doi.org/10.3390/rs8050362. 
Jaafar, Hadi H., Ahmad, Farah A. (2015) Crop yield prediction from remotely sensed vegetation indices and primary productivity in arid and semi-arid lands. International Journal of Remote Sensing, 36.18: 4570-4589.

Ji, S., Zhang, C., Xu, A., Shi, Y., Duan, Y. (2018) 3D convolutional neural networks for crop classification with multi-temporal remote sensing images. Remote Sensing, 10(1), 75.

Krzyżanowski J. T. (2018) Dywersyfikacja upraw jako element „zazielenienia” w krajach Unii Europejskiej - czy to właściwe rozwiązanie? Ekonomika i Organizacja Gospodarki Żywnościowej nr 123, 91-100 DOI 10.22630/EIOGZ.2018.123.24

Kussul, Na., Lemoine, G., Gallego, J., Skakun, S., Lavreniuk, M. (2015) Parcel based classification for agricultural mapping and monitoring using multi-temporal satellite image sequences. In Proceedings of the International Geoscience and Remote Sensing Symposium, Milan, Italy, pp. 165-168. https://doi.org/10.1109/IGARSS.2015.7325725.

Kussul, Nb., Skakun, S., Shelestov, A., Lavreniuk, M., Yailymov, B., Kussul, O. (2015) Regional scale crop mapping using multi-temporal satellite imagery. The International Archives of Photogrammetry, Remote Sensing and Spatial Information Sciences, 40(7), 45. https://doi.org/10.5194/isprsarchives-XL-7-W3-45-2015.

Lambert M-J., Traore P. C. S., Blaes X., Defourny P. (2018) Estimating smallholder crops production at village level from Sentinel-2 time series in Mali's cotton belt, Remote Sensing of Environment, 216, 647-657, doi: 10.1016/j.rse.2018.06.036.

Li, M., Ma, L., Blaschke, T., Cheng, L., Tiede, D. (2016) A systematic comparison of different object-based classification techniques using high spatial resolution imagery in agricultural environments. International Journal of Applied Earth Observation and Geoinformation, 49, 87-98. https://doi.org/10.1016/j.jag.2016.01.011.

Lillesand, T., Kiefer, R. W., Chipman, J. (2014) Remote sensing and image interpretation, John Wiley \& Sons.

Loudjani P., Angileri V., Milenov P., Fasbender D., Devos W. (2015) Technical guidance for the On-The-Spot check of Ecological Focus Areas (EFA) requirements, JRC, DS-CDP-201509 .

Łączyński A. (2016) Pilot Surveys Aimed at Methodological Improvement in Agrienvironmental Statistics and the Development of Grasslands Statistics. Final report. The Central Statistical Office of the Republic of Poland; Grant agreement 08413.2014.0052014.687.

MARS Bulletins (2020), https://agri4cast.jrc.ec.europa.eu/ (access in December, 2020)

Matton, N., Canto, G., Waldner, F., Valero, S., Morin, D., Inglada, J., Arias, M., Bontemps, S., Koetz, B., Defourny, P. (2015) An Automated Method for Annual Cropland Mapping along the Season for Various Globally-Distributed Agrosystems Using High Spatial and Temporal Resolution Time Series. Remote Sensing, 7, 13208-13232. https://doi.org/10.3390/rs71013208.

Milenov P., Fasbender D., Loudjani P. (2015) Technical guidance for the On-The-Spot checks of Crop Diversification, JRC, DSDS--CDP CDP-2015-08. 
Notice No.1 Ogłoszenie Nr 1 Prezesa Agencji Restrukturyzacji i Modernizacji z dnia 17 września 2019 r. w sprawie wielkości średniej powierzchni gruntów rolnych w gospodarstwie rolnym w poszczególnych województwach oraz średniej powierzchni gruntów rolnych w gospodarstwie rolnym w kraju w 2019 roku, www.arimr.gov.pl (access in November, 2020)

Proposal for a Regulation of the European Parliament and of the Council establishing rules on support for strategic plans to be drawn up by Member States under the Common agricultural policy (CAP Strategic Plans) and financed by the European Agricultural Guarantee Fund (EAGF) and by the European Agricultural Fund for Rural Development (EAFRD) and repealing Regulation (EU) No 1305/2013 and Regulation (EU) No 1307/2013 (...) COM/2018/392 final - 2018/0216 (COD).

Regulation (EU) No 1307/2013 of the European Parliament and of the Council of 17 December 2013 establishing rules for direct payments to farmers under support schemes within the framework of the common agricultural policy (...) http://data.europa.eu/eli/reg/2013/1307/oj.

Ray DK, Mueller ND, West PC, Foley JA (2013) Yield Trends Are Insufficient to Double Global Crop Production by 2050. PLoS ONE 8(6): e66428. https://doi.org/10.1371/journal.pone.0066428.

Schmedtmann, J., Campagnolo, M. (2015) Reliable Crop Identification with Satellite Imagery in the Context of Common Agriculture Policy Subsidy Control. Remote Sensing, 7, 9325-9346. https://doi.org/10.3390/rs70709325.

Shelestov, A., Lavreniuk, M., Kolotii, A., Vasiliev, V., Shumilo, L., Kussul, N. (2017) Cloud Approach to Automated Crop Classification Using Sentinel-1 Imagery. In Proceedings of the 207 conference on Big Data from Space, Toulouse, https://doi.org/doi: 10.2760/383579.

Sitokonstantinou V., Papoutsis J., Kontoes Ch., Lafarga Arnal A., Pilar Armesto Andrés A., Garraza Zurbano J. A. (2018) Scalable Parcel-Based Crop Identification Scheme Using Sentinel-2 Data Time-Series for the Monitoring of the Common Agricultura Policy. Remote Sensing, 10(6), https://doi.org/10.3390/rs10060911.

Skakun, S., Kussul, N., Shelestov, A. Y., Lavreniuk, M., Kussul, O. (2016) Efficiency assessment of multitemporal C-band Radarsat-2 intensity and Landsat-8 surface reflectance satellite imagery for crop classification in Ukraine. IEEE Journal of Selected Topics in Applied Earth Observations and Remote Sensing, 9(8), 3712-3719. https://doi.org/10.1109/JSTARS.2015.2454297.

Sonobe, R., Yamaya, Y., Tani, H., Wang, X., Kobayashi, N., Mochizuki, K. I. (2017) Assessing the suitability of data from Sentinel-1A and 2A for crop classification. GIScience \& Remote Sensing, 54(6), 918-938.

Stankiewicz, K. (2006) The Efficiency of Crop Recognition on ENVISAT ASAR Images in Two Growing Seasons. IEEE Transactions on Geoscience and Remote Sensing, 44(4), 806-814. https://doi.org/10.1109/TGRS.2006.864380.

Stefanski J., Mack B., Waske B. (2013) Optimization of object-based image analysis with Random Forests for land cover mapping, IEEE Journal of Selected Topics in Applied Earth Observations and Remote Sensing vol. 6 no. 6, 2429-2504.

Valero, S., Morin, D., Inglada, J., Sepulcre, G., Arias, M., Hagolle, O., Dedieu, G., Bontemps, S., Defourny, P., Koetz, B. (2016) Production of a Dynamic Cropland Mask by Processing Remote Sensing Image Series at High Temporal and Spatial Resolutions. Remote Sensing, 8, 55. https://doi.org/10.3390/rs8010055. 
van der Linden, S., Rabe, A., Held, M., Jakimow, B., Leitão, P., Okujeni, A., Schwieder, M., Suess, S., Hostert, P. (2015) The EnMAP-Box-A toolbox and application programming interface for EnMAP data processing. Remote Sensing, 7, 11249-11266. https://doi.org/10.3390/rs70911249.

Vuolo, F., Neuwirth, M., Immitzer, M., Atzberger, C., Ng, W. T. (2018) How much does multitemporal Sentinel-2 data improve crop type classification? International Journal of Applied Earth Observation and Geoinformation, 72, 122-130.

Wicka A., Parlińska A. (2019) Evaluation of Subsidized Crop Insurance in Poland. Annals of the Polish Association of Agricultural and Agribusiness Economists, Vol. XXI No. (3). doi: 10.5604/01.3001.0013.2822.

Yang, C., Everitt, J. H., Murden, D (2011) Evaluating high resolution SPOT 5 satellite imagery for crop identification. Computers and Electronics in Agriculture, 75(2), 347-354. https://doi.org/10.1016/j.compag.2010.12.012.

Received: 2020-05-21

Reviewed: 2020-07-07 (undisclosed name), 2020-08-13 (undisclosed name)

Accepted: 2020-12-18 